\title{
The contribution of cultural capital to students' mathematics achievement in medium and high socioeconomic gradient economies
}

\begin{abstract}
The present study addresses the issue of how different forms of cultural capital may influence children's mathematics achievement in economies with different socioeconomic gradients. Data from 73,178 parent-child dyads from ten economies with different socioeconomic gradients who participated in the Program for International Student Assessment (PISA) 2012 were analyzed using hierarchical linear modeling. The cultural capital variables examined comprised the availability of home educational resources and parental educational expectations of their children. Results showed that after controlling for parent education, student gender, and student history of repeating grades in the past, there were statistically significant main and interaction effects (home educational resources $\mathrm{X}$ parent education, and parental educational expectations $\mathrm{X}$ parent education) of cultural capital on student achievement. Furthermore, these effects explained more student achievement variance in high than medium socioeconomic gradient economies $(7.45 \%$ versus $2.82 \%$ respectively). In particular, the main effects for parental educational expectations, and interaction effect between parental educational expectations and parent education were more pronounced in high as compared to medium socioeconomic gradient economies. Overall, the results underscore the challenges confronting low-SES parents who aspire social mobility for their children, and the need for high-SES parents to strategically 'activate' their cultural capital advantages to benefit their children's achievement maximally.
\end{abstract}

\section{Keywords}

Cultural capital, Bourdieu, objectified, embodied 


\section{Introduction}

In the quest for equitable learning outcomes, debates on the reproductive effects of social origins on students' academic achievement have consistently crept into the policy agenda for many governments. Indeed, recent meta-analytic evidence showed that socioeconomic status (SES), as an indicator of social origins, moderately correlated with student achievement at 0.27 , explaining approximately $7 \%$ of student achievement variance (Hattie, 2009). ${ }^{1}$ Not surprisingly then, many sociologists have dedicated their research programs to investigating this salient issue. In particular, some scholars have focused on the different predictive value of SES across countries, and consequently describe countries as varying in terms of their socioeconomic gradients with respect to student achievement (Caro \& Mirazchiyski, 2012; Willms 2006, 2010). According to this classification, low socioeconomic gradient countries are countries where student achievement is less predicted by their SES, and vice versa (Willms, 2006).

Some scholars have scrutinized familial processes in their examination of how SES confer learning advantages or disadvantages for students. In particular, many of them employ Bourdieu's (1986) cultural capital theory as their conceptual framework in their studies. The appeal of cultural capital theory is understandable since it embodies many key ideas underpinning theories explaining the phenomenon of social reproduction in academic achievement (Lucas \& Beresford, 2010). These ideas include students from higher SES backgrounds being equipped with the requisite competence and skills at home (human capital theory), receiving encouragement from significant individuals to excel academically (status attainment theory), and being

\footnotetext{
${ }^{1}$ Hattie (2009) reported a Cohen's $d$ of 0.57 for the SES-achievement relationship. This is equivalent to a Pearson's $r$ of $0.27\left[0.57 / \sqrt{ }\left(0.57^{2}+4\right)\right]$, assuming equal sample sizes of subgroups (Borenstein, Hedges, Higgins, \& Rothstein, 2009).
} 
perceived as being more competent by virtue of their parents' social status (credentialing theory), thereby maintaining the status quo in social stratification (Marxist and reproduction theories). The rich intellectual underpinnings of cultural capital theory provide the conceptual tools to understand the phenomenon of social reproduction, and hence will also be employed to frame the present study. The aims of the present study are thus to examine the predictive effects of familial cultural capital on students' academic achievement in countries varying in their socioeconomic gradients.

\section{Cultural capital theory}

According to cultural capital theory, variations in students' academic achievement may be attributed to the advantages that they could appropriate from the availability of capital associated with their socioeconomic backgrounds. More specifically, students growing up in a higher SES family are argued to have more cultural capital, and would therefore be able to benefit from them in their learning (Bourdieu, 1986). Studies of cultural capital have either examined parents/children's familiarity with high-brow cultural elements, or the evaluative standards of educational institutions (Kingston, 2001; Lamont \& Lareau, 1988). The cultural capital must be used for sociocultural exclusion, so that parents from higher social classes would be able to pass on their advantages to their children, thereby perpetuating their hegemony in a stratified society. The latter perspective, involving familiarity with schools' emphases and evaluation, would be adopted in this study as there is evidence that the cultural perspective may be less predictive of student achievement in some contexts (Lamont \& Lareau, 1988; Lareau \& Weininger, 2003). Among the different manifestations of 
cultural capital, objectified and embodied cultural capital will be examined in this study.

\section{Objectified cultural capital}

Objectified cultural capital refers to home educational resources that enable students from privileged backgrounds to learn the dispositions, values, perceptions, knowledge, and skills that are valued by teachers in schools. Researchers typically measure home resources by asking participants about the availability of study facilities, books, and educational technology. Furthermore, most studies have reported a positive association between the availability of such cultural capital and students' learning (Attewell \& Battle, 1999; Byun, Schofer, \& Kim, 2012; Gilleece, Cosgrove, \& Sofroniou, 2010; Jaeger, 2009, 2011; Tramonte \& Willms, 2010; Xu \& HampdenThompson, 2012). As such, effects of the availability of home educational resources on student achievement will be examined in the present study. The availability of home resources epitomizes the premium parents place on children's learning, and their desire to give their children the most conducive conditions to support the latter's learning. Both of these attitudes are emblematic of embodied capital to be discussed next.

\section{Embodied cultural capital}

Embodied cultural capital refers to a multitude of attributes conducive to academic achievement that students can appropriate from their higher SES parents. It comprises values and attitudes propitious to learning (e.g., value of academic diligence); tastes and preferences for intellectual pursuits (e.g., via watching documentaries); and mastery of academic competencies and skills (e.g., high-order thinking skills, 
assertiveness). These attributes are aligned to those emphasized in the formal school system, and may also positively influence teachers' perceptions of the children. Therefore, students imbued with these attributes are able to benefit from their schooling (Bourdieu, 1986).

In particular, this study examines the effect of one important type of embodied cultural capital on student achievement, namely parental educational expectations of their children. Parental expectations reflect their values regarding what is desirable and achievable for their children (Dumais, 2002). These expectations may then shape their interactions with their children, and influence children's own educational expectations and effort in their academic pursuits. In the absence of perfect information on opportunities in the labor market later on, children may also use their expectations to guide them to make pragmatic 'rational' decisions (Hodkinson \& Sparkes, 1997). Notwithstanding the importance of this variable, parents (as opposed to children's) educational expectations will be examined in this study for three reasons. First, the two variables have been found to be highly correlated (Wildhagen, 2009), so measuring any one variable will suffice. Between the two, parental expectations are preferred as they are more influenced by the parents' own perceptions and experiences, whereas children's expectations may be influenced by perceptions of their own prior academic ability and therefore serve as a proxy instead of predictor of their subsequent achievement levels. The literature reviewed shows that parental expectations for their children were positively associated with the latter's academic outcomes (Pearce \& Lin, 2007; Redford Johnson, \& Honnold, 2009). For example, Redford and colleagues (2009) found that educational expectations for children, held by parents and children, positively predicted children's academic achievement as measured by grade point averages (GPAs) and standardized test 
scores. In line with Bourdieu and Passeron's (1979) assertion that parents from higher social classes have 'the eye for a good investment which enables one to get the best return on inherited cultural capital in the scholastic market or on scholastic capital in the labor market' (p. 82), it is expected that students whose parents have higher educational expectations for them would benefit from this embodied cultural capital and consequently, have higher levels of mathematics achievement.

\section{Cultural capital X SES}

In addition to the main effects of objectified and embodied cultural capital, parents' SES could also have additional moderating effects on the contribution of cultural capital (home educational resources and parental educational expectations) to academic achievement.

\section{Home educational resources $X$ SES}

First, higher SES parents may be more cognizant of where to obtain more up-to-date resources, and would have the economic means to acquire these more expensive resources. Students with educational resources at home will also derive additional benefits from the presence of highly educated parents (Giacquinta, Bauer, \& Levin, 1993). These parents may have more pedagogical knowledge on how to integrate these resources in the concerted cultivation of their children (Lareau, 2011). They could discuss with their children the learning process involving the use of the resources, address learning difficulties confronted by their children students while using these resources, advise their children on effective ways to use the educational resources, or model how they themselves would use these resources. They may also be more competent in monitoring the usage and effectiveness of the resources. Indeed, 
the transformative potential of these economic resources would be enhanced when students could access parents who possess educational qualifications (Bourdieu, 1985). Therefore, it is expected that higher SES students who have more home resources will have higher levels of achievement than lower SES students.

However, a review of the literature suggests that the results on the moderating effects of SES on objectified cultural capital are mixed. For example, Attewell and Battle (1999) reported that the positive association between the availability of home computers and academic achievement for eighth graders was strengthened for students with higher SES parents. Xu and Hampden-Thompson (2012) also found that in countries with minimal government intervention in schooling, eight-graders with parents assuming jobs with high occupational status benefited more from home resources as compared to students whose parents had less prestigious occupations. However, Roscigno and Ainsworth-Darnell (1999) found that the learning benefits for tenth-graders from home resources were similar regardless of their family's SES.

\section{Educational expectations X SES}

Students would also benefit from having parents who have high educational expectations for them, and who are themselves highly educated. Highly educated parents have benefited from schooling in the past, acquiring dispositions that enable them to embody the rules of the game that are necessary for success in the educational field. Metaphorically, each of these parents may be likened to the 'fish in water' that 'does not feel the weight of the water' and that 'takes the world about itself for granted' (Bourdieu \& Wacquant, 1992, p. 127). These parents are able to imbue the requisite dispositions in students to enable the latter to also replicate their educational success in future. For instance, they could use their past educational experience and 
knowledge of the working world to advise their children on learning and test-taking strategies, teacher and school expectations, university admission requirements, and study and career options. In so doing, they effectively form a bridge between their past and their children's future, equipping their children with valuable cultural capital in the process so as to ensure the latter's educational success (Reay, 2004). Therefore, it is expected that higher SES students with higher parental expectations will have higher levels of achievement than lower SES students.

\section{Differential effects in countries with different socioeconomic gradients}

The main and SES moderated effects of cultural capital are also expected to vary with the socioeconomic gradient of different countries.

\section{Home educational resources}

First, countries with higher socioeconomic gradients may have education systems which are horizontally segregated (Willms, 2010). In these systems, schools vary in terms of the socioeconomic profiles of students they admit (e.g., admissions based on students' place of residence). For instance, private schools or special educational programs in public schools also contribute to horizontal segregation if they appeal more to higher SES families (Willms, 2010). Additionally, principals may welcome the enrolment of higher SES children to meet accountability standards in student performance (because these students tend to have higher achievement levels) or to enhance the school's reputation in the community (Ho, 2009; Hong \& Youngs, 2008). Therefore, higher SES students have a greater probability of entering popular schools that are more resourced and that produce higher student achievement, while lower SES students are resigned to joining less-resourced and lower-performing schools. 
The higher SES students in the higher-performing schools in turn benefit from higher instructional quality, higher curricular relevance and comprehensiveness, more instructional time, and more challenging assignments (Willms, 2010). These educational processes require students to make more optimal use of their home educational resources to support their learning at school. In contrast, lower SES students, suffering the double disadvantages of low SES and attendance at lowperforming schools, would be able to partially compensate for their poorer learning quality at school if they have more home educational resources. Consequently, home educational resources are expected to contribute more to student achievement in countries with higher socioeconomic gradients, as compared to countries with lower gradients.

Furthermore, there is more latitude for higher SES parents to use their knowledge, skills, and resources to support their children's use of the home educational resources in these schools in high socioeconomic gradient countries (Willms, 2002). For instance, more educated parents would have more opportunities to use their knowhow to coach their children to do research using the Internet in order to complete more challenging school assignments. Therefore, SES is expected to have a greater positive moderating effect on the contribution of home resources to student achievement in high socioeconomic gradient countries.

\section{Educational expectations}

Countries could also have higher socioeconomic gradients if schools have practices that provide different educational offerings to students according to their academic abilities (i.e., so-called vertical segregation; Willms, 2010). In these schools, students may be assigned to different classes depending on their demonstrated prior academic 
abilities. Consequently, parents may form more accurate educational expectations of their children and in turn are better able to predict the latter's academic achievement in higher socioeconomic gradient countries, as compared with lower gradient countries.

In particular, higher SES students may have a head-start in their learning and therefore demonstrate higher prior ability levels. These students may then be more likely to be assigned to higher ability classes where they learn more challenging materials and where teachers articulate greater confidence of the students (Condron, 2007; Stevens \& Vermeersch, 2010). In contrast, lower SES students may be concentrated in lower ability classes. In either case, parents are then able to more optimally harness their knowledge, skills, and resources to realize these more accurate educational expectations they have of their children in higher (as compared to lower) socioeconomic gradient countries. This may be exemplified by parents selecting intellectually enriching classes for high-ability children or procuring educational support services for low-ability children with learning needs. Therefore, it is expected that the positive moderating effect of SES on the contribution of parental academic expectations on student achievement will be stronger in higher, as opposed to lower, socioeconomic gradient countries.

\section{Method}

\section{Participants}

Participants were parents and students who participated in the Program for International Student Assessment (PISA) 2012 conducted by Organization for Economic Cooperation and Development (OECD). PISA 2012 measured the proficiency of approximately 500,000 15-year-old students from 65 economies in 
applying their knowledge and skills learned in reading, mathematics, and science to authentic problems. However, parent- and child-reported data were only collected for ten of these economies. Data from these ten economies were analysed in the present study. These ten economies were divided into two groups based on the magnitude of their SES gradients (as measured by the correlations between student SES and achievement; Willms, 2010). Following Hemphill's (2003) empirically derived guidelines on correlation magnitude, medium SES gradient economies were deemed to be those whose SES-achievement correlations were between .2 and .3 (Hong Kong, Italy, Macao, Mexico, South Korea). In contrast, high SES gradient economies were those whose SES-achievement correlations were at least .4 (Croatia, Chile, Portugal, Belgium, Hungary). Parent or child cases with missing data for any of the variables investigated were excluded, resulting in 73,178 parent-child cases for analysis.

\section{Measures}

Data on the following variables from the PISA 2012 dataset were used in the analysis. In PISA 2012, students' mathematics achievement was the focal outcome variable of investigation. The focus on mathematics achievement is timely in view of the higher educational and career opportunities in science, technology, engineering, and mathematics in knowledge-based economies that are available to students with strong mathematics credentials (Museus, Palmer, Davis, \& Maramba, 2011). Furthermore, prior research has demonstrated that mathematics and science achievement are equally susceptible to SES and cultural capital effects as is reading (Attewell \& Battle, 1999; Dixon-Román, 2013). In PISA 2012, students were not administered the complete set of mathematics items by design, and therefore each item had missing responses. This made it impossible to estimate achievement scores 
for each student. To overcome this limitation, the results of individual students were aggregated to produce scores for groups of students in PISA 2012. For each student then, the estimated distribution of mathematics scores of students similar to him or her in terms of responses to the assessment and background items were represented by a set of five 'plausible values' (PVs) (Hopstock \& Pelczar, 2011). The five PVs were highly correlated with each other at 0.93 , and therefore, the mean of the five PVs was used as the dependent variable in the HLM analysis ${ }^{2}$.

Parents' highest educational attainment was measured using fathers and mothers' responses to items measuring their highest level of schooling completed $(1=$ Did not complete primary education, 2 = Completed primary education, $3=$ Completed lower secondary education, $4=$ Completed upper secondary education that provided direct access to labor markets or to non-university tertiary education, $5=$ Completed upper secondary education that provided access to university level or nonuniversity tertiary education). The average of these responses was then used to indicate the average highest educational attainment between the parents (a proxy for parents' SES).

The availability of home educational resources was obtained by adding up student responses on the availability of study desk, students' own room, quiet place to study, computer for school work, educational software, Internet access, books for school work, technical reference books, and dictionary at home $(1=Y e s ; 0=N o)$. Parents' educational expectations were measured by the highest level of education parents expected their children to attain $(1=$ Lower secondary education; $2=$ Upper secondary education that provided direct access to labor markets or to non-university tertiary education; $3=$ Upper secondary education that provided access to university

\footnotetext{
${ }^{2}$ This measurement approach has been employed elsewhere (e.g., Atar \& Atar, 2012).
} 
level or non-university tertiary education; 4 = Post-secondary, non-tertiary education; $5=$ Short practical, technical, or occupationally specific programs leading to professional qualifications; 6 = Bachelor degree or higher).

Information on students' gender and prior academic ability were used as controls in the analysis. Student gender was coded as 0 for female and 1 for male. Students also responded to three items indicating whether they had ever repeated a grade at the primary, lower secondary, and upper secondary level using a three-point scale $(1=$ No, never; 2 = Yes, once; $3=$ Yes, twice or more). These responses were added up to form a measure of students' prior academic ability (Repeat). The correlations, and means and standard deviations of the variables are summarized in Tables 1 and 2 respectively.

Insert Tables 1 and 2 here

\section{Procedure}

PISA 2012 involved all 34 OECD and 31 partner economies (OECD, 2013). All participating economies followed standardized procedures outlined in the technical standards and manuals provided. In addition, students, school principals, and parents (in some economies) completed related questionnaires pertaining to student learning.

\section{Results}




\section{Parent education and cultural capital}

Results for the medium SES gradient economies showed that $33.0 \%$ of parents had average educational attainments not exceeding lower secondary education, $29.7 \%$ had upper secondary education that provided access to labor markets or to non-university tertiary education, and $37.3 \%$ had upper secondary education that provided access to university level or non-university tertiary education. To examine if students whose parents were more highly educated had higher levels of home resources and parental expectations, one-way analyses of variance (ANOVAs) were conducted for the three groups of students with different parent education levels. Results showed that the three groups of students had different levels of home resources, $F(2,55,324)=$ $5,360.46, p<.01, \eta^{2}=.16$, and parental expectations, $F(2,55,324)=970.92, p<.01$, $\eta^{2}=.03$. Results of follow-up tests (Tamhane) conducted to evaluate pairwise differences among the group means were all statistically significant. Therefore, students with higher parent education had higher levels of home resources and parental expectations than students with lower parent education in medium SES gradient economies.

In the high SES gradient economies, the majority of parents completed upper secondary education that provided access to university level or non-university tertiary education (53.1\%). Dividing the remaining parents into two groups with as equal cell sizes as possible resulted in $19.1 \%$ of parents being classified as having education not exceeding lower secondary level and $27.8 \%$ of parents as having completed upper secondary education that provided direct access to labor markets or to non-university tertiary education. ANOVA results for the three groups of students with different parent education levels showed that they also had different levels of home resources, $F(2,17,848)=534.04, p<.01, \eta^{2}=.06$, and parental expectations, $F(2,17,848)=$ 
$1,081.08, p<.01, \eta^{2}=.11$. Results of follow-up tests (Tamhane) conducted to evaluate pairwise differences among the group means were all statistically significant. Therefore, students with higher parent education had higher levels of home resources and parental expectations than students with lower parent education in high SES gradient economies.

\section{Main and interactive effects of cultural capital}

Two-level hierarchical linear modelling (HLM) with restricted maximum likelihood estimation was employed to account for the plausible correlations between mathematics achievement scores of students from the same school (Raudenbush \& Bryk, 2002). Models predicting students' mathematics achievement were examined for medium and high SES gradient economies separately. To enhance the interpretability of the results and to minimize the problem of multi-collinearity arising from the inclusion of interaction terms, centered independent variables were used in all the HLM models.

HLM results for the medium SES gradient economies (Table 3) showed that $40.89 \%$ and $59.11 \%$ of the variance in students' mathematics achievement occurred at levels 1 and 2 respectively (Model 1). This suggested the utility of using HLM models which took into account the non-independence of mathematics achievement scores of students who belonged to the same school.

When parent education, and students' gender and prior academic ability variables were included (Model 2), results showed that students with higher parent education levels ( $\beta=5.86$ ) had higher levels of mathematics achievement, while girls $(\beta=-22.24)$ and students who repeated grades $(\beta=-25.89)$ had lower mathematics 
achievement, $p<.01$. When compared to model 1 , the percentage of level 1 variance in model 2 decreased by $5.28 \%$.

In model 3, these variables remained significant at the .01 level (parent education, $\beta=3.51$; Female, $\beta=-23.02$; Repeat, $\beta=-23.57$ ). Results also showed that students with more home resources $(\beta=2.10)$ and higher parental expectations $(\beta=$ 9.59) had higher mathematics achievement levels, $p<.01$. The decrease in the parent education coefficient from 5.86 (model 2) to 3.51 (model 3), and the statistical significance of the cultural capital variables indicated that the latter explained some of the SES effects on achievement. The $2.59 \%(7.87 \%-5.28 \%)$ decrease in level 1 variance for model 3 when compared to model 2 also showed that the cultural capital variables were useful predictors of student achievement.

In model 4, these different variables remained statistically significant at the .01 level. More specifically, students with higher parent education levels $(\beta=3.74)$ had higher levels of mathematics achievement, while female students $(\beta=-23.02)$ and students who had repeated grades $(\beta=-23.65)$ had lower levels of mathematics achievement. At the same time, students with more home resources $(\beta=2.25)$ and higher parental expectations $(\beta=9.93)$ had higher levels of mathematics achievement. Additionally, the interactive effects between the availability of home resources and parent education $(\beta=0.56)$, and between parental expectations and parent education $(\beta=1.04)$ were all statistically significant, $p<.01$. The fact that parent education remained significant despite the inclusion of main and interaction terms involving the cultural capital variables indicated that the latter variables were not mere proxies for SES. Finally, when compared to model 1, model 4 explained $7.95 \%$ of the proportion of level 1 variance, including $0.08 \%$ attributable to the interactive effects. 
Insert Table 3 here

Turning to the high SES gradient economies, HLM results (Table 4) showed that $42.04 \%$ and $57.96 \%$ of the variance in students' mathematics achievement occurred at levels 1 and 2 respectively (Model 1). This suggested the utility of using HLM models which took into account the non-independence of mathematics achievement scores of students who belonged to the same school.

When parent education, and students' gender, and prior academic ability variables were included (Model 2), results showed that students with higher parent education levels $(\beta=12.64)$ had higher levels of mathematics achievement, while girls $(\beta=-26.87)$ and students who repeated grades $(\beta=-27.95)$ had lower mathematics achievement, $p<.01$. When compared to model 1 , the percentage of level 1 variance in model 2 decreased by $8.71 \%$. This showed that these variables were useful predictors of students' mathematics achievement.

In model 3, these variables remained significant at the .01 level (parent education, $\beta=7.72$; Female, $\beta=-28.64$; Repeat, $\beta=-24.04)$. Results also showed that students with more home resources $(\beta=1.31)$ and higher parental expectations $(\beta=$ 16.99) had higher mathematics achievement, $p<.01$. The decrease in the parent education coefficient from 12.64 (model 2) to 7.72 (model 3), and the statistical significance of two of the cultural capital variables indicated that the latter explained some of the SES effects on achievement. The additional $6.32 \%(15.03 \%-8.71 \%)$ decrease in level 1 variance for model 3 when compared to model 2 also showed that the cultural capital variables were useful predictors of student achievement. 
In model 4, the different variables continued to be statistically significant. More specifically, students with higher parent education levels $(\beta=8.45)$ had higher levels of mathematics achievement, while female students $(\beta=-28.78)$ and students who had repeated grades $(\beta=-24.15)$ had lower levels of mathematics achievement at the .01 level. At the same time, students with more home resources $(\beta=1.54)$ and higher parental expectations $(\beta=18.90)$ had higher levels of mathematics achievement, $p<.01$. Additionally, the interactive effects between home resources and parent education $(\beta=0.73, p<.05)$, and between parental expectations and parent education $(\beta=3.71, p<.01)$ were statistically significant. The significance of the parent education coefficient despite the inclusion of main and interaction terms involving the cultural capital variables indicated that the latter variables were not mere proxies for SES. When compared to model 1, model 4 explained $15.51 \%$ of the proportion of level 1 variance, including $0.48 \%$ attributable to the interactive effects.

\section{Insert Table 4 here}

\section{Cultural capital effects in different SES gradient economies}

A comparison of the $95 \%$ confidence intervals for the cultural capital variables in Model 4 between medium and high SES gradient economies showed that in high SES gradient economies, the coefficients pertaining to parental expectations, and to parental expectations $\mathrm{X}$ parent education were statistically higher than those found in medium SES gradient economies (Table 5). However, the coefficients for home resources, and home resources $\mathrm{X}$ parent education in medium and high SES gradient economies were not statistically different at the .05 level. Additionally, the cultural 
capital variables accounted for a higher proportion of student achievement variance in high SES gradient economies (7.45\%) as compared to medium SES gradient economies $(2.82 \%)$.

Insert Table 5 here

\section{Discussion}

The objectives of the present study are to examine the effects of two types of cultural capital, namely the availability of home educational resources at home and parental educational expectations of their children, on the mathematics achievement of students from medium and high socioeconomic gradient countries. Results of the HLM analyses involving 73,178 students in ten economies who participated in the PISA 2012 showed that there were both main and interactive effects of cultural capital on student achievement in the economies examined. In particular, the effects of parental expectations, and parental expectations X parent education were significantly higher in high than medium socioeconomic gradient economies. There were no significant differences in the effects of home educational resources, or home educational resources $\mathrm{X}$ parent education on student achievement between medium and high socioeconomic gradient economies. The cultural capital variables (main and interactive effects) accounted for a higher proportion of variance in high than medium socioeconomic gradient economies.

The particular finding on parent education positively moderating the effects of their expectations has profound implications for the debate on social reproduction and mobility (Buis, 2013; Jonsson, 1987). To illustrate, lower SES parents (as proxied by 
lower parent education) could have expectations of their children that are similar to those held by higher SES parents. The independent contribution of parental expectations on children's mathematics achievement suggests that lower SES children could hope to escape the trappings of their socioeconomic circumstances if they have parents who expect more of them, and by implication, might also more involved in their learning. However, the findings on the positive moderating effects of parent education indicate that high expectations per se might not be sufficient for children to surpass their peers academically. Indeed, the findings indicated that in medium socioeconomic gradient economies, student A whose parent expectations were 1 standard deviation $(S D)$ higher than student B would have an achievement score that was 9.93 points higher. Additionally, if the parent education of student A was $1 S D$ higher than that for student B, student A's score would be expected to be higher than student B by an additional 3.74 points. Therefore, student A would be expected to score a total of $13.67(9.93+3.74)$ points higher than student B. The same argument could be made for students A and B in high socioeconomic gradient economies except that the main and interaction effects were even stronger than those found in medium socioeconomic gradient economies. More specifically, student A whose parent expectations were $1 S D$ higher than student B would have an achievement score that was 18.90 points higher. Additionally, if the average parent education of student A was $1 S D$ higher than that for student B, then student A's score would be expected to be higher than student B by an additional 8.45 points. Therefore, student A would be expected to score a total of $27.35(18.90+8.45)$ points higher than student B in high socioeconomic gradient economies. These findings implied that parent expectations need to be bolstered by high parent education - a proxy for more sophisticated levels of knowledge and skills - before children could surpass their peers academically. 
Therefore, the latter finding in a way diminished the prospect of social mobility for children from lower SES backgrounds, particularly in higher socioeconomic gradient economies.

It thus appears that the effects of cultural resources (e.g., educational expectations) on student achievement would be enhanced by the presence of legitimate knowledge of the rules of the game (e.g., acquired via parent educational experiences). Indeed, many scholars have argued that transmission of social privilege is far from a natural process; rather, parents must exercise some agency with respect to their cultural capital in order to optimally benefit their children's learning (Bassani, 2007; Jaeger, 2009; Tramonte \& Willms, 2010). There is some evidence to support this perspective. First, Jaeger (2009) showed in his study that cultural capital could predict children's academic success if (a) parents possessed cultural capital, (b) transferred it to their children, and (c) children received it and used it to benefit their educational pursuits. Similarly, Tramonte and Willms (2010) alluded to the importance of parents' embodied cultural capital in their finding that cultural capital inhering in parent-child interactions had greater predictive power than parents' independent cultural participation in predicting children's schooling outcomes. Lareau and Horvat (1999) even offered the caveat that even if parents were to possess cultural capital, they must still know how to activate it in an appropriate and legitimate way as deemed by schools.

The stronger effects of parental expectations, and parental expectations $\mathrm{X}$ parent education effect on achievement in high socioeconomic gradient economies could be understood in the light of the segregation that may characterize schools in high socioeconomic gradient economies. First, schools in these economies may be more vertically segregated so that students are allocated to classes based on their 
ability levels (Willms, 2010). This educational 'tracking' enables parents to make more accurate educational expectations that subsequently correspond to their children's actual achievement. Furthermore, high SES children with higher prior ability levels by virtue of concerted cultivation from their parents (Lareau, 2011) may likely be assigned to higher ability classes. Their parents are then able to support their children's learning in order to realize their informed educational expectations in high socioeconomic gradient contexts.

In contrast to the stronger effects of parental expectations in higher socioeconomic gradient economies, there were no differences in the magnitude of home resource effects (main and 'parent education' moderated) between medium and high socioeconomic gradient economies. These results could indicate the stronger predictive efficacy of embodied vis-a-vis objectified capital on student achievement in cultural capital theory. Indeed, Bourdieu (1985) argued that it is insufficient to merely consider material resources (e.g., home resources) in the examination of social stratification and reproduction. What is equally, if not more, important is to examine how privileged parents could harness their cultural resources (e.g., embodied dispositions) to maintain sociocultural exclusion and perpetuate their class advantages. Another possible reason for the results is that the effects of home resources vary between low and high socioeconomic gradient economies, but not substantively between medium and high socioeconomic gradient economies. Therefore, future studies involving high and low socioeconomic gradient economies could be conducted to test this proposition.

Taken together, the cultural capital variables (main and interaction effects) accounted for a total of $2.82 \%$ and $7.45 \%$ of the student achievement variance in medium and high socioeconomic gradient economies respectively. Following 
Baumert, Ludtke, and Trautwein's (2006) argument that effect sizes as small as 2 to $4 \%$ were of practical significance in educational research because they were equivalent to the average learning gain in one school year, the practical implications associated with the magnitude of the effect sizes obtained in the present study were substantial. Furthermore, Hattie's (2009) synthesis of more than 800 meta-analyses on student achievement found that average effect sizes (Cohen's $d$ ) of different sources of influence (student, home, school, teacher, curricular, and teaching) ranged from only 0.23 to 0.49 . This translates to $1.31 \%$ to $5.66 \%$ in explanatory variance respectively. ${ }^{3}$ Therefore, the proportion of explanatory variance accounted for by the main and interaction effects involving cultural capital variables in the present study was consistent with what would be expected from the meta-analytic benchmarks. All these results indicated that the presence of main and interaction effects involving the different cultural capital variables helped explain some of the differences in the magnitude of socioeconomic gradients of countries. These results, premised on the availability of familial cultural capital, refined our understanding of country socioeconomic gradients that has erstwhile been explained in terms of horizontal and vertical segregation in schools (Willms, 2010).

On a conceptual level, and transcending contextual differences in terms of country socioeconomic gradients, these results suggest that parents from higher social classes might be more able to benefit their children in their learning via the transmission of their larger stock of cultural capital, thereby validating the relevance of cultural capital theory in explaining social reproduction and inequality (Strayhorn, 2010; Weininger \& Lareau, 2003; Xu \& Hampden-Thompson, 2012). It is also

\footnotetext{
${ }^{3}$ Cohen's $d$ was converted to Pearson's $r$ using the formula, $r=d / \sqrt{ }\left(d^{2}+4\right)$, assuming equal sample sizes of subgroups (Borenstein et al., 2009). The proportion of variance explained was then computed by squaring $r$.
} 
evident from the results that the possession of individual forms of cultural capital may be insufficient to ensure children's academic success. Contrariwise, it is important that these resources be optimally converted to capital for the learning benefit of children by competent parents (e.g., from higher SES backgrounds). This conclusion accords with Bourdieu's (1986) contention that cultural capital is '... a symbolically and materially active, effective capital insofar as it is appropriated by agents and implemented...' (p. 247).

Notwithstanding its contributions to the cultural capital literature, the present study suffers from two key limitations. First, the study employs secondary parentchild data collected in the PISA 2012 study, and hence is restricted to using data pertaining to only ten economies where parent-child data were collected. Therefore, findings on interactive effects pertaining to country profiles have to be interpreted as tentative pending further replication on other economies (including those with low socioeconomic gradients). Second, the study only examines very specific aspects of cultural capital, namely the availability of home educational resources and parental expectations. Obviously, there are many other potential indicators of cultural capital that could be investigated for their main and interactive effects in future studies. Future studies could address the two limitations outlined above by examining other aspects of cultural capital not covered in the present study and by collecting parentchild data from more countries.

\section{Conclusion}

The present study aims to address the question of how children's mathematics achievement is predicted by cultural capital in economies with different socioeconomic gradients. The data examined were survey responses from 73,178 
pairs of parents and their children from ten economies in PISA 2012. The forms of cultural capital investigated comprised objectified cultural capital as measured by the availability of home educational resources, and embodied cultural capital as measured by parental educational expectations of their children. HLM results provided evidence for the positive contribution of the different cultural capital variables on children's mathematics achievement. There was also support for the moderating effects of parent education on these forms of cultural capital. Additionally, the results showed that the main effect of parental educational expectations, and the interactive effect involving parent education and this variable were particularly pronounced in high as compared to medium socioeconomic gradient economies. Put together, the results underscore the challenges confronting low SES parents who aspire social mobility for their children, and the need for high SES parents to strategically 'activate' their cultural capital advantages to benefit their children's achievement maximally, especially in high socioeconomic gradient economies. 


\section{References}

Atar, H. Y. \& Atar, B. (2012) Investigating the multilevel effects of several variables on Turkish students' science achievements on TIMSS, Journal of Baltic Science Education, 11(2), 115-126.

Attewell, P. \& Battle, J. (1999) Home computers and school performance, Information Society, 15(1), 1-10.

Bassani, C. (2007) Five dimensions of social capital theory as they pertain to youth studies, Journal of Youth Studies, 10(1), 17-34.

Baumert, J., Ludtke, O. \& Trautwein, U. (2006) Interpreting effect sizes in large-scale educational assessments (Berlin, Max Planck Institute for Human Development).

Borenstein, M., Hedges, L. V., Higgins, J. P. T. \& Rothstein, H. R. (2009) Introduction to meta-analysis (New York, NY, Wiley).

Bourdieu, P. (1985) Social space and the genesis of groups, Theory and Society, 14(6), $723-744$.

Bourdieu, P. (1986) The forms of capital, in: J. G. Richardson (Ed.) Handbook of theory and research for the sociology of education (New York, NY, Greenwood).

Bourdieu, P. \& Passeron, J. C. (1979) The Inheritors, French students and their relation to culture (Chicago, IL, University of Chicago Press).

Bourdieu, P. \& Wacquant, L. J. D. (1992) An invitation to reflexive sociology (Chicago, IL, University of Chicago Press). 
Buis, M. L. (2013) The composition of family background: the influence of the economic and cultural resources of both parents on the offspring's educational attainment in the Netherlands between 1939 and 1991, European Sociological Review, 29(3), 593-602.

Byun, S.-Y., Schofer, E. \& Kim, K.-K. (2012) Revisiting the role of cultural capital in East Asian educational systems: the case of South Korea, Sociology of Education, 85(3), 219-239.

Caro, D. H. \& Mirazchiyski, P. (2012) Socioeconomic gradients in Eastern European countries: evidence from PIRLS 2006, European Educational Research Journal, 11(1), 96-110.

Condron, D. J. (2007) Stratification and educational sorting: explaining ascriptive inequalities in early childhood reading group placement, Social Problems, 54(1), 139-160.

Dixon-Román, E. J. (2013) The forms of capital and the developed achievement of Black males, Urban Education, 48(6), 828-862.

Dumais, S. A. (2002) Cultural capital, gender, and school success: the role of habitus, Sociology of Education, 75(1), 44-68.

Giacquinta, J. B., Bauer, J. A. \& Levin, J. E. (1993) Beyond technology's promise: an examination of children's educational computing at home (Cambridge, Cambridge University Press).

Gilleece, L., Cosgrove, J. \& Sofroniou, N. (2010) Equity in mathematics and science outcomes: characteristics associated with high and low achievement on PISA 2006 in Ireland, International Journal of Science and Mathematics Education, 8(3), 475-496. 
Hattie, J. (2009) Visible learning: a synthesis of over 800 meta-analyses relating to achievement (London \& New York, NY, Routledge).

Hemphill, J. F. (2003). Interpreting the magnitudes of correlation coefficients, American Psychologist, 58(1), 78-80.

Ho, E. S.-C. (2009) Educational leadership for parental involvement in an Asian context: insights from Bourdieu's theory of practice, The School Community Journal, 19(2), 101-122.

Hodkinson, P. \& Sparkes, A. C. (1997) Careership: a sociological theory of career decision-making, British Journal of Sociology of Education, 18(1), 29-44.

Hopstock, P. \& Pelczar, M. (2011) Technical report and user's guide for the Program for International Student Assessment (PISA): 2009 data files and database with U.S. specific variables (NCES 2011-025) (Washington, DC, National Center for Education Statistics, Institute of Education Sciences, U.S. Department of Education).

Hong, W.-P. \& Youngs, P. (2008) Does high-stakes testing increase cultural capital among low-income and racial minority students?, Education Policy Analysis Archives, 16(6), 1-18.

Jaeger, M. M. (2009) Equal access but unequal outcomes: cultural capital and educational choice in a meritocratic society, Social Forces, 87(4), 1943-1971.

Jaeger, M. M. (2011) Does cultural capital really affect academic achievement? New evidence from combined sibling and panel data, Sociology of Education, 84(4), 281-298.

Jonsson, J. O. (1987) Class origin, cultural origin, and educational attainment: the case of Sweden, European Sociological Review, 3(3), 229-242. 
Kingston, P. W. (2001) The unfulfilled promise of cultural capital theory, Sociology of Education, 74(4), 88-99.

Lamont, M. \& Lareau, A. (1988) Cultural capital: allusions, gaps and glissandos in recent theoretical developments, Sociological Theory, 6(2), 153-168.

Lareau. A. (2011) Unequal childhoods: class, race, and family life ( $2^{\text {nd }}$ Ed.) (Berkeley \& Los Angeles, CA, University of California Press).

Lareau, A. \& Horvat, E. M. (1999) Moments of social inclusion and exclusion: race, class, and cultural capital in family-school relationships, Sociology of Education, 72(1), 37-53.

Lareau, A. \& Weininger, E. B. (2003) Cultural capital in educational research: a critical assessment, Theory \& Society, 32(5/6), 567-606.

Lucas, S. R. \& Beresford, L. (2010) Naming and classifying: theory, evidence, and equity in education, Review of Research in Education, 34, 25-84.

Museus, S. D., Palmer, R. T., Davis, R. J. \& Maramba, D. C. (2011) Racial and ethnic minority students'success in STEM education (ASHE Higher Education Report 36(6)) (San Francisco, CA, Wiley).

OECD. (2013) PISA 2012 results in focus: what 15-year-olds know and what they can do with what they know. Available online at: http://www.oecd.org/pisa/keyfindings/pisa-2012-results-overview.pdf (accessed 11 August 2014).

Pearce, R. R. \& Lin, Z. (2007) Chinese American post-secondary achievement and attainment: a cultural and structural analysis, Educational Review, 59(1), 1936.

Raudenbush, S. W. \& Bryk, A. S. (2002) Hierarchical linear models: applications and data analysis methods ( $2^{\text {nd }}$ edition) (Thousand Oaks, CA, Sage). 
Reay, D. (2004) 'It's all becoming a habitus': beyond the habitual use of habitus in educational research, British Journal of Sociology of Education, 25(4), 431444.

Redford, J., Johnson, J. A. \& Honnold, J. (2009) Parenting practices, cultural capital and educational outcomes: the effects of concerted cultivation on academic achievement, Race, Gender \& Class, 16(1/2), 25-44.

Roscigno, V. J. \& Ainsworth-Darnell, J. W. (1999) Race, cultural capital, and educational resources: persistent inequalities and achievement returns, Sociology of Education, 72(3), 158-178.

Stevens, P. A. J. \& Vermeersch, H. (2010) Streaming in Flemish secondary schools: exploring teachers' perceptions of and adaptations to students in different streams, Oxford Review of Education, 36(3), 267-284.

Strayhorn, T. L. (2010) When race and gender collide: social and cultural capital's influence on the academic achievement of African American and Latino males, The Review of Higher Education, 33(3), 307-332.

Tramonte, L. \& Willms, J. D. (2010) Cultural capital and its effects on education outcomes, Economics of Education Review, 29, 200-213.

Weininger, E. \& Lareau, A. (2003) Translating Bourdieu into the American context: the question of social class and family-school relations, Poetics, 31, 375-402.

Wildhagen, T. (2009) Why does cultural capital matter for high school academic performance? An empirical assessment of teacher-selection and self-selection mechanisms as explanations of the cultural capital effect, The Sociological Quarterly, 50, 173-200. 
Willms, J. D. (2002) Ten hypotheses about socioeconomic gradients and community differences in children's developmental outcomes (Quebec, Human Resources Development Canada).

Willms, J. D. (2006) Learning divides: ten policy questions about the performance and equity of schools and schooling systems (Montreal, UNESCO Institute for Statistics).

Willms, J. D. (2010) School composition and contextual effects on student outcomes, Teachers College Record, 112(4), 1008-1037.

Xu, J. \& Hampden-Thompson, G. (2012) Cultural reproduction, cultural mobility, cultural resources, or trivial effect? A comparative approach to cultural capital and educational performance, Comparative Education Review, 56(1), 98-124. 
Table 1

Summary of Inter-correlations for Variables

\begin{tabular}{lccccc}
\hline Measures & 1 & 2 & 3 & 4 & 5 \\
\hline 1. MathPV & - & $.31^{* *}$ & $-.08^{* *}$ & $.36^{* *}$ & $.19^{* *}$ \\
2. Parent Education & $.26^{* *}$ & - & $-.07 * *$ & $.45^{* *}$ & $.16^{* *}$ \\
3. Repeat & $-.16^{* *}$ & $-.08^{* *}$ & - & $-.02^{* *}$ & $-.12^{* *}$ \\
4. Home Educational Resources & & & & & $.02 * *$ \\
5. Educational Expectations & $.30^{* *}$ & $.25^{* *}$ & $-.05^{* *}$ & - & $-16^{* *}$ \\
\end{tabular}

Note. Inter-correlations of variables are presented above the diagonal for medium SES gradient economies, and below the diagonal for high SES gradient economies. For all variables, higher scores are indicative of more extreme responses in the direction of the construct assessed.

${ }^{* *} p<.01$. 
Table 2

Summary of Means and Standard Deviations for Variables

$$
\begin{array}{ll}
\text { Medium SES gradient } & \text { High SES gradient } \\
\text { economies }(n=55,327) & \text { economies }(n=17,851)
\end{array}
$$

\begin{tabular}{lcc}
\hline MathPV & $490.53(92.56)$ & $503.65(90.04)$ \\
Parent Education & $3.78(1.05)$ & $4.36(0.89)$ \\
Repeat & $3.08(0.36)$ & $3.06(0.32)$ \\
Home Educational Resources & $6.71(1.93)$ & $7.60(1.36)$ \\
Educational Expectations & $5.29(1.22)$ & $5.22(1.22)$ \\
\hline
\end{tabular}

Note. Standard deviations in parentheses. 
Table 3

Fixed Effects Estimates (Top) and Variance-Covariance Estimates (Bottom) for Models of the Predictors of Mathematics Achievement (Medium SES Gradient Economies)

\begin{tabular}{|c|c|c|c|c|}
\hline Parameter & Model 1 & Model 2 & Model 3 & Model 4 \\
\hline \multicolumn{5}{|c|}{ Fixed effects } \\
\hline Intercept & $468.46^{* *}(1.41)$ & $481.40 * *(1.37)$ & $483.64 * *(1.32)$ & $482.80 * *(1.33)$ \\
\hline Parent Education & & $5.86^{* *}(0.30)$ & $3.51 * *(0.31)$ & $3.74 * *(0.31)$ \\
\hline Female & & $-22.24 * *(0.55)$ & $-23.02 * *(0.54)$ & $-23.02 * *(0.54)$ \\
\hline Repeat & & $-25.89 * *(0.76)$ & $-23.57 * *(0.75)$ & $-23.65 * *(0.75)$ \\
\hline Home Educational Resources & & & $2.10 * *(0.17)$ & $2.25^{* *}(0.17)$ \\
\hline Educational Expectations & & & $9.59 * *(0.25)$ & $9.93^{* *}(0.26)$ \\
\hline Home Educational & & & & $0.56^{* *}(0.13)$ \\
\hline \multicolumn{5}{|l|}{ Resources*Parent Education } \\
\hline Educational Expectations*Parent & & & & $1.04 * *(0.21)$ \\
\hline \multicolumn{5}{|l|}{ Education } \\
\hline \multicolumn{5}{|c|}{ Random parameters } \\
\hline Level 1 intercept & $3,523.07 * *(21.73)$ & $3,336.89 * *(20.59)$ & $3,245.78 * *(20.03)$ & $3,242.87 * *(20.02)$ \\
\hline Level 2 intercept & $5,092.76 * *(148.34)$ & $4,553.55 * *(133.55)$ & $4,210.19 * *(124.43)$ & $4,216.01 * *(124.75)$ \\
\hline Level 1 variance $(\%)$ & 40.89 & 42.29 & 43.53 & 43.48 \\
\hline Level 2 variance $(\%)$ & 59.11 & 57.71 & 56.47 & 56.52 \\
\hline Reduction in Level 1 variance $(\%)$ & & 5.28 & 7.87 & 7.95 \\
\hline \multicolumn{5}{|l|}{ when compared to Model 1} \\
\hline-2 Restricted log likelihood & $617,499.30$ & $614,344.09$ & $612,684.22$ & $612,641.95$ \\
\hline Akaike's Information Criterion & $617,503.30$ & $614,348.09$ & $612,688.22$ & $612,645.95$ \\
\hline Schwarz's Bayesian Criterion & $617,521.14$ & $614,365.94$ & $612,706.07$ & $612,663.79$ \\
\hline
\end{tabular}

Note. Standard errors in parentheses. $* p<.05 . * * p<.01$. 
Table 4

Fixed Effects Estimates (Top) and Variance-Covariance Estimates (Bottom) for Models of the Predictors of Mathematics Achievement (High SES Gradient Economies)

\begin{tabular}{|c|c|c|c|c|}
\hline Parameter & Model 1 & Model 2 & Model 3 & Model 4 \\
\hline \multicolumn{5}{|c|}{ Fixed effects } \\
\hline Intercept & $491.49 * *(2.45)$ & $508.51 * *(2.37)$ & $511.56^{* *}(2.15)$ & $510.39 * *(2.14)$ \\
\hline Parent Education & & $12.64 * *(0.62)$ & $7.72^{* *}(0.62)$ & $8.45^{* *}(0.63)$ \\
\hline Female & & $-26.87 * *(0.94)$ & $-28.64 * *(0.91)$ & $-28.78 * *(0.91)$ \\
\hline Repeat & & $-27.95 * *(1.43)$ & $-24.04 * *(1.38)$ & $-24.15^{* *}(1.38)$ \\
\hline Home Educational Resources & & & $1.31 * *(0.35)$ & $1.54 * *(0.35)$ \\
\hline Educational Expectations & & & $16.99 * *(0.45)$ & $18.90 * *(0.49)$ \\
\hline Home Educational & & & & $0.73 *(0.33)$ \\
\hline \multicolumn{5}{|l|}{ Resources*Parent Education } \\
\hline Educational Expectations*Parent & & & & $3.71^{* *}(0.38)$ \\
\hline \multicolumn{5}{|l|}{ Education } \\
\hline \multicolumn{5}{|c|}{ Random parameters } \\
\hline Level 1 intercept & $3,542.21 * *(38.45)$ & $3,233.78 * *(35.09)$ & $3,009.96 * *(32.67)$ & $2,992.89 * *(32.49)$ \\
\hline Level 2 intercept & $4,884.20 * *(252.59)$ & $4,342.14 * *(223.27)$ & $3,516.78 * *(182.93)$ & $3,476.08 * *(181.09)$ \\
\hline$\%$ Level 1 variance & 42.04 & 42.68 & 46.12 & 46.27 \\
\hline$\%$ Level 2 variance & 57.96 & 57.32 & 53.88 & 53.73 \\
\hline $\begin{array}{l}\% \text { Reduction in Level } 1 \text { variance } \\
\text { when compared to Model } 1\end{array}$ & & 8.71 & 15.03 & 15.51 \\
\hline -2 Restricted log likelihood & $199,303.10$ & $197,647.37$ & $196,253.32$ & $196,145.58$ \\
\hline Akaike's Information Criterion & $199,307.10$ & $197,651.38$ & $196,257.32$ & $196,149.58$ \\
\hline Schwarz's Bayesian Criterion & $199,322.68$ & $197,666.95$ & $196,272.90$ & $196,165.16$ \\
\hline
\end{tabular}

Note. Standard errors in parentheses. $* p<.05 . * * p<.01$. 
Table 5

95\% Confidence Intervals of Cultural Capital Variables in Models 4

\begin{tabular}{lcc}
\hline & \multicolumn{2}{c}{ Country SES gradients } \\
& Medium & High \\
\hline Home Educational Resources & $(1.91,2.59)$ & $(0.85,2.23)$ \\
Educational Expectations & $(9.42,10.44)$ & $(17.94,19.86)$ \\
Home Educational Resources*Parent Education & $(0.32,0.81)$ & $(0.09,1.36)$ \\
Educational Expectations*Parent Education & $(0.63,1.45)$ & $(2.96,4.46)$ \\
\hline$\%$ Level 1 variance explained by cultural capital variables (main & 2.82 & 7.45 \\
and interactive effects) & & \\
\hline
\end{tabular}

